\title{
A Profile; Dr Harry R. Hahn M.D., Medallist of the International Medical Society of Paraplegia
}

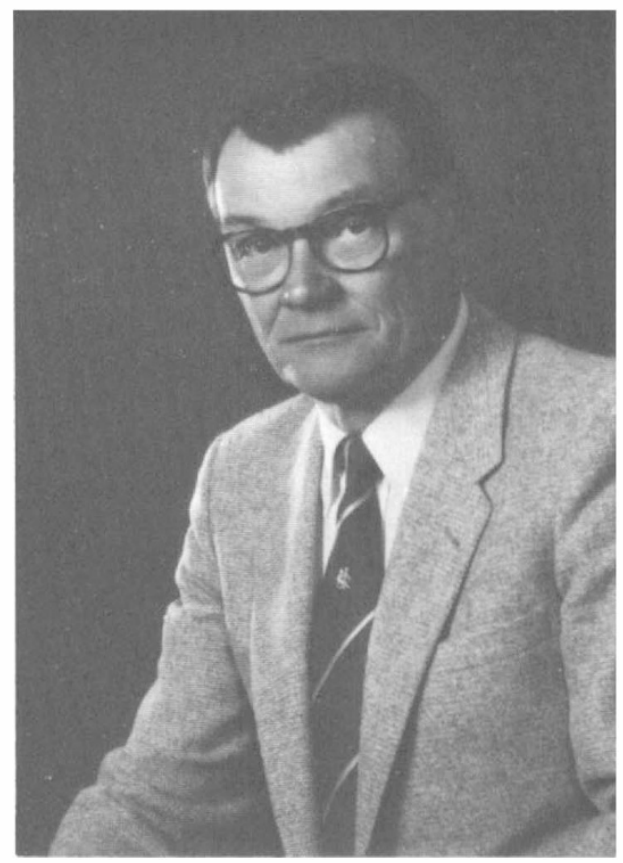

Harry R. Hahn, M.D., was elected Medallist of the International Medical Society of Paraplegia for 1986 at the Annual Scientific Meeting in Oslo, Norway in recognition of his many contributions to the care of the spinal cord injured.

His enthusiastic leadership, combined with his exceptional clinical, teaching, and organisational skills was instrumental in the development of a complete system of care for spinal cord and for brain injured patients at the Craig Hospital in Denver, Colorado, U.S.A. Throughout his illustrious career, Dr Hahn has remained primarily a clinician. His major interest has been the welfare of his patients.

In addition to his clinical duties, Dr Hahn was Director of Education at Craig Hospital from 1973 to 1986, and at his insistence the hospital established a 1 year fellowship in spinal cord injury. He was president of the Medical Staff at Craig from 1973 through 1979 and Medical Director from 1980 until his retirement in the fall of 1985 .

Dr Hahn has been a staunch advocate of the concept of the continuing care for the spinal cord injured under the direction of a primary physician who specialises in their care. He was the founding Director of Neurotrauma Units at 
the Swedish Hospital (1974) and the St Anthony's Hospital (1978) in Denver, Colorado. As a consequence, he and his associates, most of whom he had personally trained, became primary care physicians for spinal cord and brain injured persons from the first day of their injuries throughout their entire course of initial treatment, rehabilitation, and follow-up care.

Dr Hahn was born in Logansport, Indiana, U.S.A., in 1925. He served in the United States Army in the South Pacific from 1943 through 1946. He received his Bachelor of Arts Degree from the University of California, Berkley in 1949. $\mathrm{He}$ is a Phi Beta Kappa. His Doctorate of Medicine is from the University of California School of Medicine, San Francisco (1952). His post-graduate education included an internship and one year surgical residency (1952-1954) at the Kaiser Foundation Hospital in San Francisco, California. It was during this early period that he became exposed to the plight of the spinal cord injured. His major duties in those days were to repair 'bed sores' and write orders for morphine. Following this formal training Dr Hahn had a unique experience. He accepted a position as Medical Director for a large construction firm building major projects in Afghanistan (1954-1957), Iran (1957-1961), and Indonesia (1961-1965). He spent 11 years looking after the diverse medical and surgical problems of the workers, their families, and the local natives in those ancient lands.

Returning to the U.S.A. in 1965, Dr Hahn completed a 2 year residency in Physical Medicine and Rehabilitation at Stanford Medical School, Palo Alto, California. He is a diplomate of the American Board in that specialty, and is a fellow of the American Academy of Physical Medicine and Rehabilitation, and an Associate Member of the American Academy of Orthopedic Surgeons. He was a founding member of the American Spinal Injury Association, and has been a member of the International Medical Society of Paraplegia since 1969.

Throughout his years of clinical practice, Dr Hahn was an indefatigable leader and worker. He treated his patients and staff with kindness and respect laced with firm expectations. His professional demeanor has been a model of Teutonic efficiency. At times, 'after the flag went down', he has revealed his Celtic nature. Standing on top of a table, glass in hand, he has been known to lead the assembled group in singing, followed by a spirited recitation of Kipling and other assorted poems.

Symbolic of all the true clinicians that dedicate their lives to serving the needs of the spinal cord injured, this year's medal has been awarded to Harry R. Hahn, M.D.

John S. Young, M.D. 